\title{
2006-1509: ACADEMIC CAPABILITY PRODUCING ECONOMIC DEVELOPMENT: A SUCCESS STORY
}

\section{Phillip Sanger, Western Carolina University}

Phillip Sanger is an Associate Professor of Engineering and Technology and serves as the Director of the Center for Integrated Technologies at Western Carolina University. He holds a B.A. in Physics from Saint Louis University and earned his M.S. and Ph.D. in Nuclear Engineering from the University of Wisconsin Madison. Technology development including MRI magnets and $\mathrm{SiC}$ power devices plus economic development has been his career foci.

\section{Aaron Ball, Western Carolina University}

Aaron K. Ball is an Associate Professor and serves as the Graduate Program Director in Engineering and Technology at Western Carolina University in Cullowhee, North Carolina. He holds a B.S. and an M.S. from Appalachian State University, and earned his doctorate from Virginia Polytechnic Institute and State University. His areas of interests include fluid power, advanced machining, prototyping systems, and applied research.

\section{Michael Clare, Western Carolina University}

Michael Clare is a graduate student of Engineering Technology at Western Carolina University pursing a Masters of Science in Technology. He earned his B.S at Western Carolina University in 2004 and, at the time of this project, Mr. Clare was a senior in the Engineering Technology program.

\section{Chip Ferguson, Western Carolina University}

Chip W. Ferguson is an Assistant Professor of Engineering Technology at Western Carolina University and earned his B.S and M.S. at the University of Southern Mississippi, and currently a doctoral candidate at Western Carolina University. His industrial experience includes mechanical and fluid power systems and teaches parametric modeling and prototyping at Western Carolina.

\section{John D. Graham, Western Carolina University}

John D. Graham, and who is know to all of his colleagues as Monty, is the electronics applications engineer providing technical support for all rapid prototyping in the Center for Integrated Technologies at Western Carolina University. Mr. Graham received his BS in Electronics Engineering Technology in 1995 and his M.S. in Technology in 2003, both from Western Carolina. His current project endeavors include rehabilitative technology and reverse engineering. 


\title{
Academic Capability Producing Economic Development: A Success Story
}

\begin{abstract}
This success story demonstrates the direct application of academic skills and capabilities to the growth and expansion of small Western North Carolina businesses while enhancing the educational experience for WCU engineering students. Watauga Opportunities Inc. (WOI) is a non-profit organization in Boone, NC that employs and trains people with disabilities to enter the workforce. Their company specializes in forming heated plastic sheets into a variety of packaging products. WOI turned to the Western Carolina University engineering team for assistance in securing a new business area: thermoformed packaging for Christmas tree ornaments. WCU engineering undergraduate students and professors generated a 3D parametric model that described the complex geometry. A high fidelity mold was then made from a highheat resistant plastic called polyphenolsulfone (PPSF) which was used by WOI to generate thermoformed packaging prototypes directly from the rapid prototyped mold. Within two days of receiving the mold, WOI was able to thermoform parts in their plant delighting the surprised customer with prototypes four days after New Years Day. The successful outcome of the project opened the door to subsequent development work and led to orders valued at over \$1M for products that had been previously manufactured in China. This paper discusses the challenges of the project and demonstrates an exciting application of graduate student and faculty talents to impact the economic development of the regional community.
\end{abstract}

\section{Introduction}

Over the past several years, Western Carolina University, under the leadership of Chancellor John Bardo, has championed the engagement of the WCU faculty, students, and resources with the economic growth of Western North Carolina. Western Carolina University is a regional comprehensive institution founded in 1889 with a distinguished history of teaching and learning for the region. Since research and development were not within the institution's initial areas of focus, the infrastructure for applied research and supporting industry was limited. In a Regional Summit entitled "Meeting Western North Carolina's Needs through Higher Education," one of the recommendations was to explore "engagement in non-traditional and creative ways" providing new access by regional entities to the resources of the university ${ }^{1}$. The commitment to engagement is leading to its incorporation into the tenure and promotion process having importance equal to instruction and scholarship. The Kimmel School of Construction Management, Engineering and Technology has taken the lead in making WCU engagement a reality with the region and developing the needed performance metrics. The focus on engagement led to the creation in 2004 of the Center for Integrated Technologies (CIT) positioned within the Kimmel School. The mission of the CIT is to match the Kimmel School's expertise and resources to Western North Carolina's needs by forming effective partnerships to grow the region's economy and improve the quality of life for its people. The dual goals of the CIT are: economic development and learning enhancement. Its mission comes to life through direct student/faculty projects and technical assistance to companies in our regions. At the time of this writing, 13 members out of the 21 faculty members have already been connected to engagement projects resulting in improvements to plant logistics, enhancements to productivity, , 
assistive tooling for persons with disabilities and new hydraulic pump designs. The participation has been broadly based with faculty from all curricula of the Kimmel School (construction management, engineering technology, telecommunications, electrical and computer engineering and electrical engineering) being represented in the engagement effort. In December of 2004, in the middle of final exams, an opportunity presented itself which would come to demonstrate the potential of this mission on the economic growth of the region.

Watauga Opportunities Inc.(WOI) is a non-profit organization in Boone, NC that employs and trains people with disabilities to enter the workforce. The revenue generated by these products allows WOI to provide a broad range of skill training to persons with disabilities. Teaching and reinforcing interpersonal skills, stress coping skills, and communication skills in a confidence building environment together with hands-on production experience are key components of the services that WOI provides to the community. Their company specializes in products that are made by forming heated plastic sheets into a variety of packaging shapes. In early December of 2004, WOI was approached by Raush Industries (Raush), a maker of Christmas ornaments in Gastonia, N.C., to produce the plastic packaging for their product. Raush only provided a sample of an extremely flimsy sample from which WOI was to generate prototypes demonstrating that WOI had the skills and talents to be a reliable supplier. While WOI had the knowledge and skills to actually make the packaging, they did not have the design skills to reverse engineer a mold of this complexity from a sample of the product. To add to the challenge, they were only given three weeks to provide prototypes and these three weeks came over the Christmas and New Years holiday season. Having heard of Western Carolina University's commitment to support economic growth in the region, WOI turned to the WCU engineering faculty for assistance.

\section{Approach to the Challenge}

WCU engineering graduate and undergraduate students and professors, working over the Christmas holidays, solved the problem. The first task was the reverse engineering of the extremely flexible and thin packaging sample in order to define the required dimensions and design constraints for the mold. The preliminary requirements of the mold were then obtained and a $3 \mathrm{D}$ solid model of the mold was created by utilizing the parametric design software package Pro/Engineer shown in Figure 1. The concave depression requiring complex and multifaceted features was a stimulating vehicle for expanding the student's knowledge in modeling. This level of detail was common on external surfaces but rarely seen and experienced on internal depressions. Furthermore, the product required a crisscrossing pattern of very shallow groves on the top surface. This feature can be seen in figure 1 in red across the face. This feature resulted in

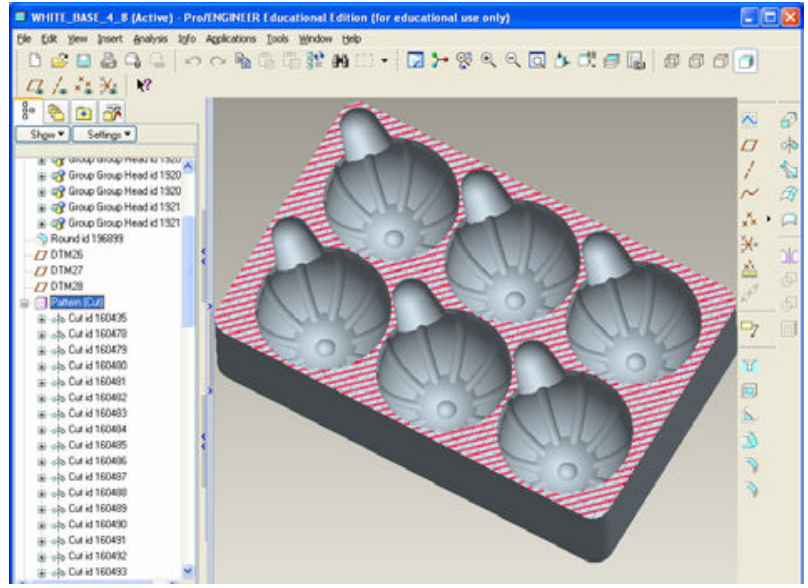

Figure 1. A parametric model of the mold was generated in Pro-Engineer software based on measurements taken from the sample. 
massive and unworkable design files. The team then created a layered model structure which was more manageable. The 3D solid model allowed the design team to check form and fit functions of the mold while still in the initial drafting stage shown in figure 2. After several design iterations, the solid model was converted into a Stereo Lithography (.STL) file, which allows the exchange of data between solid model and rapid-prototyping format.

Stratasys' Titan Fused Deposition Modeling (FDM) machine, like most rapid prototyping technologies, builds the model layer by layer and employs a controller software package to

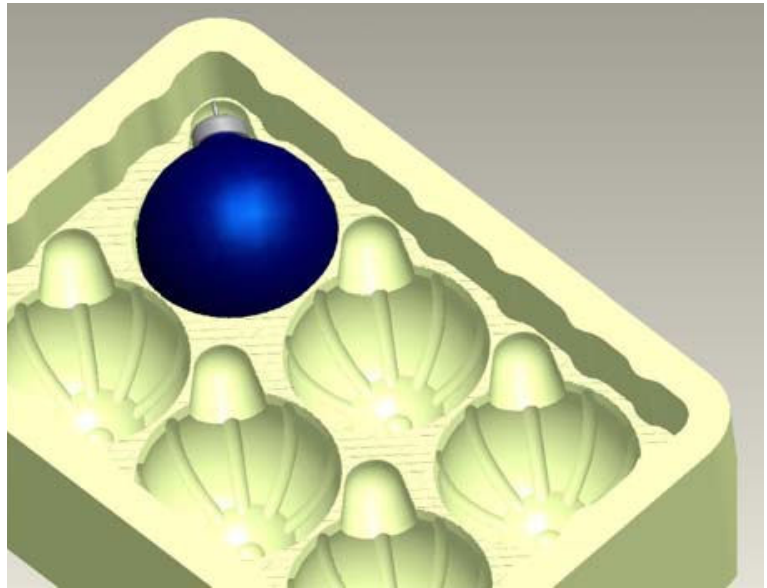

Figure 2. The form/fit/function of the mold was verified in the virtual models prior to fabrication. perform pre-build operations such as slicing the model. The STL file of the mold model was imported into Insight, the Titan's software package. The geometry of the mold design allowed for the negation of support material, which in turn allowed for a faster build time. Upon the creation of all boundary curves and toolpaths, a Compressed Model Build file (.CMB) was downloaded to the Titan which began building the model.

The Titan, shown Figure 3, employs an extrusion process to build the models and has a build envelope of $406 \mathrm{~mm}$ x $355 \mathrm{~mm}$ x $406 \mathrm{~mm}$ ( 16 " x 14" x 16") and a tolerance between 0.127 to $0.038 \mathrm{~mm} / \mathrm{mm}(0.005$ and $0.0015 \mathrm{in} / \mathrm{in})$, depending upon the overall size of the part. This FDM machine uses a gantry controlled extruder head that has the ability to move in the $\mathrm{X}$ and $\mathrm{Y}$-axis direction while the build table can be raised and lowered in the Z-axis as needed. The initial foundation layer is extruded by the head which follows the predetermined tool path. The build chamber, which provides a controlled environment for the solidification process, is maintained at a temperature lower than the melting point of the material. Once the first layer is complete, the table is lowered so that subsequent layers can be extruded. If support structures are required, a separate nozzle or extruder die is employed to extrude the associated support material enabling
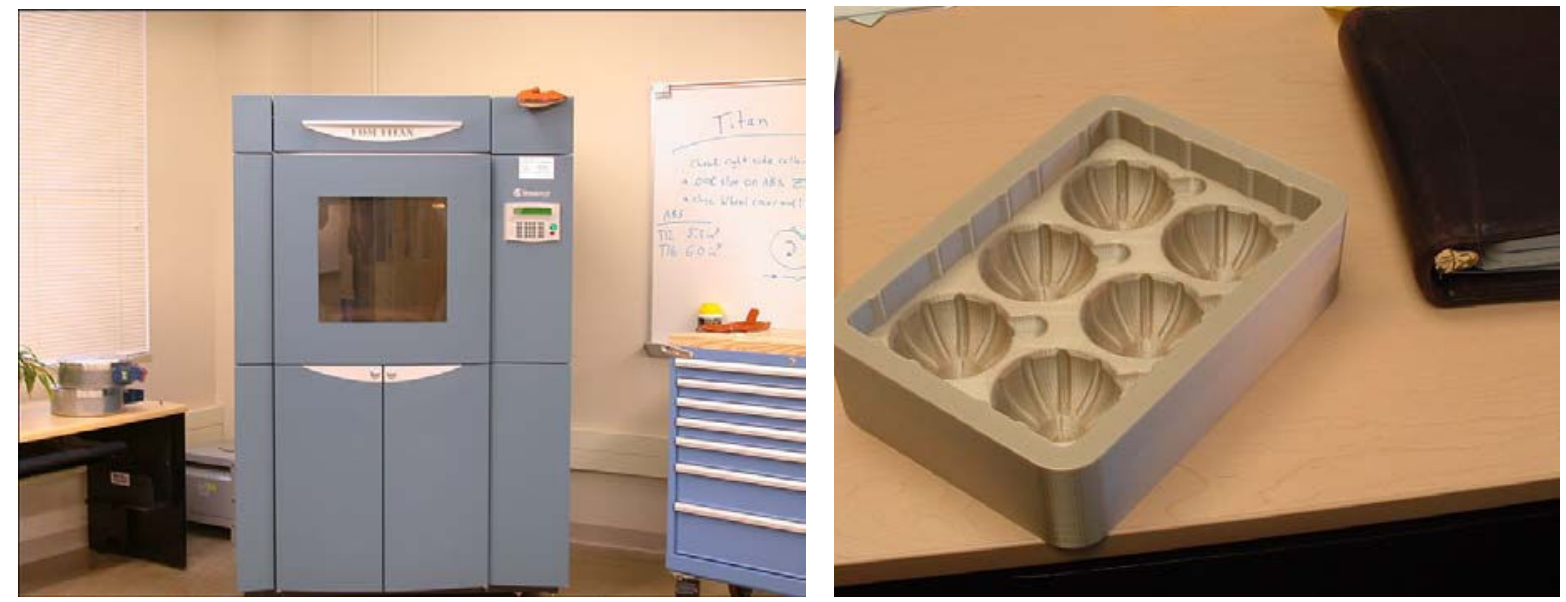

Figure 3 Stratasys' FDM Titan machine (on the left) required 72 hours to produce the PPFP mold (on the right) 
the construction of complicated part geometries. After the prototype part was completed, the water soluble support material is removed from the finished part.

The FDM Titan is capable of producing parts in three different thermoplastic materials: acrylonitrile butadiene styrene (ABS), polyphenylsulfone (PPSF), or polycarbonate (PC). Based on Stratasys data sheets ${ }^{2}$, PPSF was chosen for the WOI mold due to its favorable strength and properties at elevated temperatures which would allow the prototype products to be directly thermoformed on the model ${ }^{3}$. The selection of PPSF for this project is innovative considering that thermoforming usually requires the machining of metal molds requiring over eight weeks of lead time. Using PPSF, the team went directly from computer model to high fidelity mold in less than a week. Over 72 hours of rapid prototyping machine time was required over the Christmas weekend to deliver the prototype mold in less than 3 weeks start to finish to WOI. Within two days of receiving the mold, WOI was able to thermoform parts in their plant and stunned the customer with prototypes four days after New Year's Day. Only one additional design iteration with minor dimensional adjustments was needed to achieve the tight tolerances needed for this product. This process demonstrated to Raush Industries that the WOI/WCU team was up to the task of reverse engineering the packaging, building the prototype, and producing good parts in an extremely tight timeframe.

The success of this project has had far reaching impact. The rapid turn-around and quick response that the WOI/WCU team demonstrated on this project broke the confidence barrier that many suppliers must penetrate when approaching potential new customers. Superior and timely delivery allowed Raush to consider the team as a viable contributor to their new product development. Raush had been developing an advanced product pack using suppliers in the Far East. The time between design iterations was measured in months while the style and artistic features that they desired were difficult to communicate and realize in the product samples. In addition, this new packaging concept needed to address Christmas tree ornaments decorated with glitter. The tolerances were critical since the decorative glitter rubbed off if the package was too tight. On the opposite range of the tolerances, the ornament could be broken if the package was too loose. To quickly converge on the proper design, a series of models focusing only on the pocket design were then produced. These models had two pockets per assembly shown in Figure 4 and served to quickly validate the pocket design.
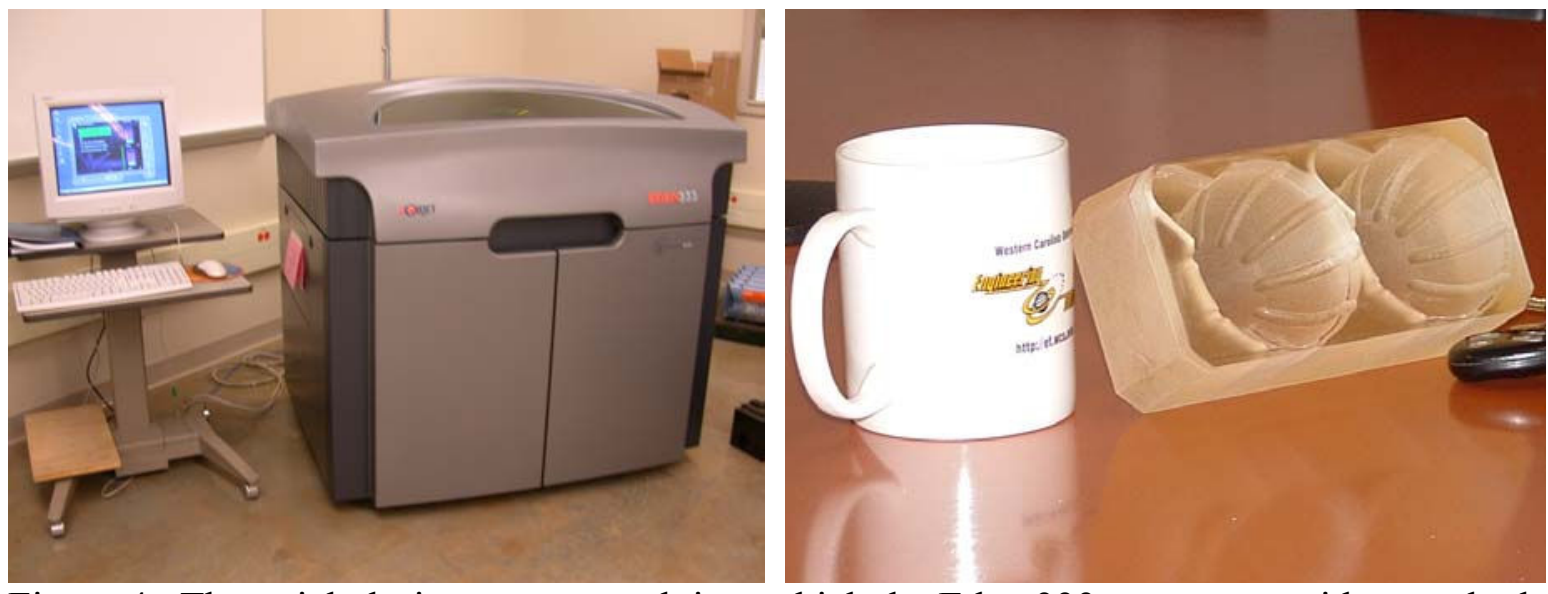

Figure 4. The quick design turn around time which the Eden 333 process provides resulted in a rapid convergence on the pocket design shown on the right. 
For this series of models, the team switched to the Eden 333 rapid prototyping system shown in Figure 4. This system uses photopolymer jetting technology to precisely deposit ultraviolet (UV) sensitive resins in fine layers down to 16 microns. Parts up to $340 \mathrm{~mm} \times 325 \mathrm{~mm} \times 200 \mathrm{~mm}$ can be built in this machine. These modeling materials are proprietary acrylics cured by exposure to UV light. Build resolution is 600 dpi for $\mathrm{X}$ axis, $300 \mathrm{dpi}$ for $\mathrm{Y}$ axis, and $1600 \mathrm{dpi}$ for $\mathrm{Z}$ axis. The Eden 333 can produce smooth surface/fine featured parts very quickly with minimum postbuild cleanup. Despite the fact that the useable temperature range of this acrylic is less than the temperatures required for thermoforming, the team felt that the acrylic would hold up long enough to validate the design. The rapid prototyping speed was essential to meeting the goals of the project. The gamble paid off. Within eight weeks the design parameters were validated and a final design of package determined.

\section{Reflection and Impact}

The business opportunities that this new product area opens up for WOI are impressive. The almost $\$ 1,000,000$ of orders for this product were sufficient to justify the capital investment of $\$ 350,000$ for new thermoforming equipment. Nevertheless these sizable orders consumed only $30 \%$ of the machine's capacity opening the door to the development of new customers. The university/industry partnership provided rapid product realization allowing WOI to quickly develop their customer's trust and confidence, an essential ingredient of a solid commercial relationship. The reverse engineering process so aptly demonstrated during this process offered substantial compression of the time to production. The impact on the students of real world conditions from a challenging project was profound. The complex geometry stretched their capabilities and expanded their knowledge and skills in modeling. In this project, time was of the essence and the undergraduate students quickly recognized the pressures of the real world. And finally the project afforded WCU students a glimpse into the commercial world where rapid response and a shorten time to market can make the difference of success and failure. The Marketing Association of Rehabilitation Centers presented the team with the 2005 Directors Award in recognition of the contribution that the WCU team made to Watauga Opportunities with this project ${ }^{4}$.

\section{Acknowledgements}

The authors would like to commend WCU graduate students Preston McCrary and William Extine without whom this project would not have been feasible.

\section{Bibliography}

1. “A Regional Summit: Meeting Western North Carolina's Needs Through Higher Education”, February 21, 2003, Western Carolina University, http://www.wcu.edu/chancellor/presentations/regionalsummit Feb2003.html

2. Stratasys, FDM Material Properties, retrieved November 29, 2005 from http://www.stratasys.com

3. Polyphenylsulfone, retrieved December 1, 2005 http://www.ebigchina.com/ebcps/4/pd/1501175 
4. Neal, Dale (2005, March 28). WCU center creating opportunity- rapid prototyping group's ingenuity means good things for area. Asheville Citizen-Times, WNC Business, W3-W4.

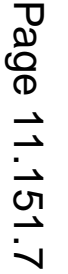

